\title{
Hyperbaric oxygen therapy for chronic post-concussive syndrome
}

\author{
Matthew C Davis ${ }^{1}$, Mohammadali M Shoja ${ }^{2 *}$, Shane R Tubbs ${ }^{2}$ and Christoph J Griessenauer ${ }^{1}$
}

\begin{abstract}
In this editorial, the value of hyperbaric oxygen therapy in the management of chronic post-concussive syndrome following mild traumatic brain injury is discussed.
\end{abstract}

Keywords: Hyperbaric oxygen, Traumatic brain injury, Outcome

Traumatic brain injury (TBI) affects roughly 10 million people worldwide each year, and is a leading cause of death and disability among all demographics, disproportionately affecting young adults [1]. TBI is defined as an external mechanical insult to the brain in the form of penetration, acceleration, rotational forces, or blast waves resulting in temporary or permanent impairment in brain function. TBI is further categorized by etiology, damaged area of the brain, and severity (mild, moderate or severe). In the United States, $80 \%$ of TBI cases are mild, with loss of consciousness less than thirty minutes, retrograde amnesia of less than one day and Glasgow Coma Scale (GCS) on presentation of 13-15 [2].

Following even mild TBI, many patients experience a range of symptoms grouped together under the heading of post-concussive syndrome (PCS). Symptoms include alterations in executive function, depression, anxiety, headache, dizziness, and impairment in memory. Approximately one in five patients with PCS will experience these symptoms for greater than six months following their injury [3]. PCS is a clinical diagnosis, and many patients with mild TBI will have normal-appearing conventional CT and MRI scans. Specialized functional or metabolic sequences such as SPECT (Single Photon Emission Computed Tomography), functional MRI, or $\mathrm{CT}$ perfusion may detect subtle impairments in regional activity to explain the post-concussive phenomenon [4].

Therapy for post-concussive syndrome is typically supportive. Physical, occupational and behavioral therapies are the mainstay of treatment, and the vast majority of

\footnotetext{
* Correspondence: shoja.m@gmail.com

2Department of Neurosurgery, Children's of Alabama, Birmingham, AL, USA Full list of author information is available at the end of the article
}

patients return to their neurologic and psychological baseline in under a year. Recently, hyperbaric oxygen therapy (HBOT) has been used as a potential therapeutic option for patients experiencing chronic PCS symptoms [5]. HBOT involves the administration of oxygen at supra-atmospheric pressures and increased fractions of inspired air.

HBOT is increasingly used to treat the long-term sequelae of a variety of neurologic conditions, including ischemic stroke, subarachnoid hemorrhage, and recently mild TBI [5-7]. HBOT is thought to induce neuroplasticity, support repair of injured brain tissue, and stimulate angiogenesis [8]. Although considered a largely benign intervention, increasing pressures beyond four to five absolute atmospheres is associated with oxygen toxicity and lowering of the seizure threshold [9]. Due to its favorable safety profile, limitations to the use of $\mathrm{HBOT}$ are mainly financial and practical. Therapeutic sessions require a significant time investment on the part of the patient, and a single session typically costs several hundred dollars [10].

Treatment paradigms are not standardized across studies on the use of HBOT in TBI. Atmospheric pressure, length of treatment, and number of sessions all vary between studies. With rare exception, 100\% oxygen is used [11]. A typical HBOT session might consist of thirty to sixty minutes administration of $100 \%$ oxygen at 1.5 to 2.5 times atmospheric pressure. Patients typically undergo twenty to sixty sessions over four to twelve weeks, based on the condition being treated [12]. The optimal paradigm for HBOT in TBI remains to be determined.

Invasive and expensive interventions such as HBOT are associated with a greater placebo effect than benign 
and cheap interventions [13]. Additionally, blinded studies on HBOT are difficult to perform, as patients are able to sense even minor changes in atmospheric pressure. In a recent study, Boussi-Gross et al. attempt to address this issue through the use of a prospective, randomized, crossover trial to evaluate the impact of HBOT on patients with chronic post-concussive syndrome years after mild TBI [14]. Fifty six patients with PCS of greater than one year's duration were randomized to receive forty HBOT sessions either before or after a two month control period. Patients were evaluated by standardized cognitive testing, quality-of-life questionnaires, and SPECT imaging at several points during the study period. Both groups showed statistically significant improvements in cognitive function, quality of life, and fronto-temporal perfusion on SPECT imaging following HBOT, but not following the control period. All SPECT analysis was blinded to the laboratory and clinical data, and showed increased brain perfusion in regions critical for higherorder cognition and memory.

While the study design allowed for both inter- and intra-group comparisons before and after HBOT administration, it did not completely address the potential role of the placebo effect in these patients. Other investigators have utilized control groups in which patients were randomized to increased atmospheric pressures with a normal atmospheric partial pressure of oxygen. In general, these studies have not shown a benefit of either increased oxygen tension or increased pressures to 1.5 to 2 times atmospheric pressure $[15,16]$. However these studies do not address any potential therapeutic benefit of higher pressures in the absence of increased oxygen tension. As of 2012, the Cochrane Collaboration stated that HBOT could not be routinely recommended for PCS following TBI [17]. Inadequate power in many studies, variable therapeutic protocol, and methodological flaws all prevented a positive recommendation.

Nevertheless, the study of Boussi-Gross et al. provides a compelling argument that whatever the underlying therapeutic mechanism, patients show improved cognitive function and cerebral perfusion after HBOT, and report improved quality of life. PCS is a debilitating complication of mild TBI, currently without any definitive treatment options. These results are worth future investigation in the form of larger randomized, blinded controlled trials, as well as longer follow-up periods to determine the durability of any HBOT effect.

\section{Competing interest}

The authors declare that they have no conflict of interest in connection with this manuscript.

\section{Author details}

${ }^{1}$ Department of Neurological Surgery, University of Alabama at Birmingham, Birmingham, AL, USA. ${ }^{2}$ Department of Neurosurgery, Children's of Alabama, Birmingham, AL, USA.
Received: 6 February 2014 Accepted: 24 March 2014

Published: 9 April 2014

\section{References}

1. Hyder AA, Wunderlich CA, Puvanachandra P, Gururaj G, Kobusingye OC: The impact of traumatic brain injuries: a global perspective. NeuroRehabilitation 2007, 22:341-353.

2. McCrea M, Iverson GL, McAllister TW, Hammeke TA, Powell MR, Barr WB, Kelly JP: An integrated review of recovery after mild traumatic brain injury (MTBI): implications for clinical management. Clin Neuropsychol 2009, 23:1368-1390.

3. Bazarian JJ, Wong T, Harris M, Leahey N, Mookerjee S, Dombovy M: Epidemiology and predictors of post-concussive syndrome after minor head injury in an emergency population. Brain Inj 1999, 13:173-189.

4. Kato T, Nakayama N, Yasokawa Y, Okumura A, Shinoda J, Iwama T: Statistical image analysis of cerebral glucose metabolism in patients with cognitive impairment following diffuse traumatic brain injury. J Neurotrauma 2007, 24:919-926.

5. Harch PG, Andrews SR, Fogarty EF, Amen D, Pezzullo JC, Lucarini J, Aubrey C, Taylor DV, Staab PK, Van Meter KW: A phase I study of low-pressure hyperbaric oxygen therapy for blast-induced post-concussion syndrome and post-traumatic stress disorder. J Neurotrauma 2012, 29:168-185.

6. Griessenauer CJ, Shoja MM, Loukas M, Tubbs RS: The value of hyperbaric oxygen therapy in postoperative care of subarachnoid hemorrhage. Med Gas Res 2012, 2:29.

7. Efrati S, Fishlev G, Bechor Y, Volkov O, Bergan J, Kliakhandler K, Kamiager I, Gal N, Friedman M, Ben-Jacob E, Golan H: Hyperbaric oxygen induces late neuroplasticity in post stroke patients-randomized, prospective trial. PLoS One 2013, 8:e53716.

8. Zhang JH, Lo T, Mychaskiw G, Colohan A: Mechanisms of hyperbaric oxygen and neuroprotection in stroke. Pathophysiology 2005, 12:63-77.

9. Chavko M, Xing G, Keyser DO: Increased sensitivity to seizures in repeated exposures to hyperbaric oxygen: role of NOS activation. Brain Res 2001, 900:227-233.

10. Chuck AW, Hailey D, Jacobs P, Perry DC: Cost-effectiveness and budget impact of adjunctive hyperbaric oxygen therapy for diabetic foot ulcers. Int J Technol Assess Health Care 2008, 24:178-183.

11. McDonagh M, Hefland M, Carson S, Russman BS: Hyperbaric oxygen therapy for traumatic brain injury: a systematic review of the evidence. Arch Phys Med Rehabil 2004, 85:1198-1204.

12. Sjoberg F, Singer M: The medical use of oxygen: a time for critical reappraisal. J Intern Med 2013, 274:505-528.

13. Brim RL, Miller FG: The potential benefit of the placebo effect in shamcontrolled trials: implications for risk-benefit assessments and informed consent. J Med Ethics 2013, 39:703-707.

14. Boussi-Gross R, Golan H, Fishlev G, Bechor Y, Volkov O, Bergan J, Friedman M, Hoofien D, Shlamkovitch N, Ben-Jacob E, Efrati S: Hyperbaric oxygen therapy can improve post concussion syndrome years after mild traumatic brain injury - randomized prospective trial. PLoS One 2013, 8:e79995.

15. Cifu DX, Walker WC, West SL, Hart BB, Franke LM, Sima A, Graham CW, Carne W: Hyperbaric oxygen for blast-related post-concussion syndrome: 3-month outcomes. Ann. Neurol 2013, 75(2):277-286.

16. Walker WC, Franke LM, Cifu DX, Hart BB: Randomized, Sham-Controlled, Feasibility Trial of Hyperbaric Oxygen for Service Members With Postconcussion Syndrome: Cognitive and Psychomotor Outcomes 1 Week Postintervention. Neurorehabil Neural Repair 2013. doi:10.1177/ 1545968313516869.

17. Bennett MH, Trytko B, Jonker B: Hyperbaric oxygen therapy for the adjunctive treatment of traumatic brain injury. Cochrane Database Syst Rev 2012, 12, CD004609.

doi:10.1186/2045-9912-4-8

Cite this article as: Davis et al:: Hyperbaric oxygen therapy for chronic post-concussive syndrome. Medical Gas Research 2014 4:8. 